\title{
Choice and control for people ageing with intellectual disability in group homes
}

\author{
Ida Kåhlin, Anette Kjellberg and Jan-Erik Hagberg
}

\section{Linköping University Post Print}

\section{Tweet}

N.B.: When citing this work, cite the original article.

Original Publication:

Ida Kåhlin, Anette Kjellberg and Jan-Erik Hagberg, Choice and control for people ageing with intellectual disability in group homes, 2016, Scandinavian Journal of Occupational Therapy, (23), 2, 127-137.

http://dx.doi.org/10.3109/11038128.2015.1095235

Copyright: Informa Healthcare

http://informahealthcare.com/

Postprint available at: Linköping University Electronic Press

http://urn.kb.se/resolve?urn=urn:nbn:se:liu:diva-127631 


\section{Title}

Choice and control for people ageing with intellectual disability in group homes

Running headline Choice and control in group homes

\section{Authors}

Kåhlin, Ida ${ }^{\mathrm{a}}$, Kjellberg, Anette ${ }^{\mathrm{b}}$ and Hagberg, Jan-Erik ${ }^{\mathrm{a}}$

${ }^{a}$ National Institute for the Study of Ageing and Later Life (NISAL), Department of Social and Welfare Studies, Linköping University, Norrköping, Sweden.

${ }^{b}$ Faculty of Health Sciences, Department of Social and Welfare Studies, Linköping University, Norrköping, Sweden.

\section{Corresponding author}

Ida Kåhlin

Linköping University

Department of Social and Welfare Studies

National Institute for the Study of Ageing and Later Life

60174 Norrköping, Sweden

Telephone: + 4611363256

E-mail: ida.kahlin@liu.se 


\begin{abstract}
Background Many people ageing with intellectual disabilities [ID] age in place in group homes. Participation is a central concept in support and service to people with ID, but age is often a determining factor for participation among this group. Choice and control are dimensions of participation.
\end{abstract}

Aim The aim of this article is to explore how choice and control in the everyday life of people ageing with ID is expressed and performed in the group home's semi-private spaces.

Material and methods Participant observations and interviews with residents and staff were conducted in four different group homes in Sweden that had older residents.

Results We found four categories that can be understood as aspects of choice and control in the group home's semi-private spaces in the everyday life of people ageing with ID. These categories included aspects such as space and object, time and routines, privacy and a person-centred approach.

Conclusion and significance People ageing with ID are vulnerable when it comes to maintaining choice and control in various situations in the home's semi-private spaces. We argue that occupational therapists should include this occupational arena in their evaluations and interventions for people ageing with ID.

Keywords: Autonomy; Decision-making; Developmental disabilities; Empowerment; Group accommodation; Later life; Older adults; Participation; Occupational justice 


\section{Introduction}

People with intellectual disabilities [ID] experience age related conditions and issues earlier and quicker compared to people without disabilities. Additionally, increasingly more people with ID are reaching what society defines as old age, e.g. being retired (1-4). In Sweden, the majority of this group age in place in community based group homes where they often have lived for a long time (1). The group home is intended to be the residents' private and permanent home and should not function as or give the impression of being an institution. However, the group home is a unique residential environment. In addition to a small private apartment, a resident normally has access to spaces that are shared with other residents (5). Accordingly, the group home can be understood as being made up of both private spaces, in the form of the residents' apartments, and of common spaces, such as the common kitchen, dining and living rooms, and connecting spaces such as corridors and entrances and maybe a small garden just outside (6-7). In this study, these common spaces are called semi-private. Altogether, this set-up makes the group home unique in that it is a combination of an institutional living arrangement, an ordinary residence, and a work place for paid staff (8). This environment is, in accordance with the general Swedish disability policy, expected to ensure good living conditions for all its residents, and promote each resident's right to self-determination, empowerment, integrity and full participation in the life of the community $(5,9)$.

In Sweden, group homes are community-based and are operated in accordance with the Swedish Disability Act (5). Ever since the implementation of the normalisation principle (10) in the 1970s, the concept of participation has retained an exceptional position within disability policy, as an outcome measure of support and service related to people with ID $(9,11-12)$. Additionally, in an international context, the level of participation in the home, community, work and social arenas is 
used as an indicator of outcomes in group homes for people with ID $(8,13)$. How to measure participation and separate it from activity is, however, disputed within a wider international disability and rehabilitation context (14-16). This study uses a conceptual definition of participation based on an occupational therapy perspective $(15,17)$. This means that participation and activity are understood as pre-requisites for health (18), and have objective as well as subjective, dimensions $(14-15,19)$. In a study by Hammel et al. (14) based on focus groups with over 200 people with disabilities, participation was described as a set of values. These values included "meaningful engagement or being a part of", "personal and societal responsibilities", "having an impact and supporting others", "social connections, inclusion and membership", “access and opportunity", and "choice and control”. Respect and dignity were described as critical overarching factors influencing all participation.

In occupational therapy research, studies on participation have usually been carried out with people who are younger than 65 (20). However, age has been shown to be a determining factor when it comes to participation among people with ID. Older people with ID seem to engage in work-related, social and leisure activities to a lesser extent than their younger counterparts (21). The conditions for participation for older people with ID in everyday life and the community are thought to be closely related to contextual factors (22). Supportive social environments foster continuity, communion and a sense of coherence (23-26), and arrangements in the physical environment, such as use of technical devices, can be vital for participation for this group of people (27-30). Additionally, studies highlight that organisational and institutional factors such as disability policy, attitudes of staff, and societal values are also crucial for participation among older people with ID (23, 31-34). 
For people ageing with ID, participation can appear in diverse forms. An earlier study (22) showed that the residents' age is important for the staff's perceptions and attitudes regarding participation among older residents. In that study, the concept of participation was described both as a social contextual doing, and as an aspiration to create a sense of coherence or experience of meaning and security in the everyday life of the group home.

This study will focus on one dimension of participation; namely having choice and control, which means being able to decide what you want to do, and when and with whom you want to do it (14). Choice and control have been identified as important dimensions in conceptual analyses of different forms of participation among people with ID (35), and these dimensions are also identified as crucial by people with disabilities themselves (14). Choice and control can also be related to the concept of occupational justice. This is a concept that relates ethical, moral and political issues of justice to human occupation. Occupational justice relies on empowerment and informs person-centred approaches (36-37), which is also stated in legislation on support and service to people with ID in Sweden (5).

This study concentrate on the semi-private spaces in group homes. These spaces are important for the residents' social togetherness, but can also be used to exercise staff power and reduce resident empowerment $(6,8)$. This makes semi-private spaces an interesting context to study, particularly in relation to the older residents' individual and collective choice and control. They are especially interesting since older people with ID tend to spend more of their time at home, and in these semi-private spaces $(21-22,38)$. With this background, the aim of this study is to explore how choice and control in the everyday life of people ageing with ID is expressed and performed in the group home's semi-private spaces. 


\section{Materials and methods}

In the study, an ethnographic approach with a combination of participant observations and qualitative interviews was used (39-40). The methodological approach was chosen because it can provide rich qualitative data, and since it allows detailed description of the phenomenon being studied (41). This approach has also been described as suitable for occupational therapy research aiming to understand the impacts of environment on a person's participation (42), which is vital in this study.

\section{Study settings and informants}

We used a purposive sampling method to select study settings and to recruit informants (41). The choice of study settings was based on the inclusion criteria of being community-based group homes for people with ID, and of having older residents, i.e. people aged 50 or older. One reason for the age criterion was that there are indications that people with ID have a faster biological ageing process than others (2-3). Another reason for this criterion was that people with ID of this age, i.e. being born around or before 1960, belong to a unique generation, since many of them started their life in an institution (11). Their experiences have probably influenced their experience of ageing and later life as well as their opportunities for and experiences of participation in old age (17). In this study ID, is defined as incomplete development of the brain in the prenatal, perinatal or postnatal period before the age of 18. ID is understood to cause significant restrictions in a person's intellectual functioning and adaptive behaviour in interaction with the surrounding environment. Barriers arising in this interaction can induce a need for various types of support (43). 
Managers at the Office of Social Affairs in two municipalities in the south of Sweden served as gatekeepers (39-40) for this study. After discussions with these managers, four group homes were selected based on the inclusion criteria. They were similar with regard to staffing and resident characteristics.

In total, the group homes had 32 residents. Their mean age was 62, with the oldest resident being 90 years old. The residents had mild to profound levels of intellectual disability (43). Several also had additional disabilities such as reduced mobility, dementia or psychiatric conditions. Most residents had lived in institutional settings for most of their lives and had lived in the specific group home for up to twenty years. Half of the residents participated regularly (two to five days per week) in work-related activities outside the group home. Most residents had the majority of their at-home-meals together at the common dining table. As for the staff, a total of 45 persons, were employed in the four group homes. Most of them $(n=41)$ worked as direct care staff and provided 24-hour support with all kinds of personal care, housing and leisure activities.

The semi-private spaces that have been observed in this study were located indoors at the centre of the group home building, surrounded by corridors leading to the residents' private apartments. The semi-private spaces varied when it came to size, but had an open-plan layout for cooking, dining, and performing collective and individual activities.

\section{Procedure}

The observations and interviews were performed from August 2011 to April 2012, by the first author (IK) who had several years of experience working as an occupational therapist in group homes for people with ID. 


\section{Observation setting}

During the participant observations IK mainly acted as a "complete participant" (39), meaning that she was involved in the informants' everyday life, and in the interactions taking place in the semi-private spaces in each group home. The observations were made at various times of the day between 7AM and 10PM over a period of one month in each group home. The sessions lasted between two and five hours during which IK participated in a wide range of everyday activities. Some observed activities included interactions between staff and residents, while others included interactions only between the observer and one or several of the residents. The observations were focused on the external preconditions for choice and control in semi-private spaces (35), such as objects and spaces, and interactions between social groups such as staff and neighbours (17). Short working notes were jotted down throughout the observations, and then re-written as comprehensive filed notes at the end of each observation session (39-40).

\section{$\underline{\text { Selection procedure for the interviews }}$}

When participant observations had been conducted in each group home for about three weeks, individual interviews were performed with some of the residents and members of staff.

When it came to interviews with residents, the inclusion criteria were that the informant should be around 50 years of age or older, and have the communication and interaction skills required for participating in an interview. The initial observations made it possible for the first author to gather significant information about the residents' communication and interaction skills, habits and interests. This information was used in the sampling of interview informants as well as in preparing and carrying out the interviews. Of the 32 residents in the group homes, twelve 
individuals, five men and seven women, met the criteria and agreed to be interviewed. Their mean age was 64 and they had moderate to mild ID. Nine of these informants were involved in daily work-related activities.

The inclusion criterion for the staff interviews was that they should have their primary work place in one of the four group homes. However, representativeness with regard to gender, age, length of work experience and position was requested. Of the 45 staff members, 15 individuals were included. Thirteen of them were women and two were men (a proportion that reflected the gender bias within the care staff groups). Three were executive managers, one was a team leader, and the rest were direct-care staff at the group home. The mean age for this group was 44 , and their total working years of providing services for people with intellectual disability ranged from two to 35 $(m=15)$. The executive managers and the team leader had a university degree in social work or equivalent, and the direct care staff had an educational level corresponding to upper secondary school.

\section{$\underline{\text { Interview setting }}$}

All resident interviews took place in each informant's apartment, with only IK and the informant present, and lasted between 20 and 50 minutes. The staff interviews lasted for one to two hours, and were conducted in a location adjacent to the group home. Semi-structured interview guides with broad topics related to the aim of the study served as a checklist in interviews with both staff and residents $(41,44)$. Open questions were asked with the aim of obtaining as complete a description as possible of the informants' experiences of the phenomenon being studied (45). The resident interview questions were focused on internal preconditions for choice and control in 
semi-private spaces (35), such as the experience of decision-making in daily life. The staff interview questions were focused on external preconditions, which can be exemplified as staffs' attitudes towards participation in everyday life of older residents. Probing (41) was used during all interviews with staff and residents in order to clarify and make sure that the interviewer understood what the informant meant.

As the intellectual limitations of persons with ID often influences their ability to communicate, the interviewer frequently needed to reformulate the questions in a more concrete way. Using pictures was a complementary strategy used to support the informants in understanding and answering the questions. The value of this approach is supported by a number of studies $(12,46-$ 49). In some interviews, the informant was given written questions, and in one case the informant's personal photo album was used. The first author's pre-understanding of ID in general, and specifically of each informant, was significant in planning and performing the interviews in an individualized way.

All interviews were recorded with permission from the informants, and these were transcribed verbatim by IK.

\section{Data analysis}

The data analysis was performed in two phases, with the help of the computer software package MAXQDA (version 10, 2011, Marburg, VERBI Software). In the first phase the authors used the field notes and adopted a descriptive conventional content analysis, which is generally used in studies aiming to describe a phenomenon (50), which in this case was how choice and control in the everyday life of people ageing with ID were expressed and performed in the group home's 
semi-private spaces. As a starting point the field notes were read through several times by all authors. Thereafter the authors marked units of meaning related to the aim of the study. This was done in accordance with the first impression of the units of meaning. The units of meaning included descriptions of a wide range of everyday situations in the semi-private spaces, which included interactions in which the residents' choice and control were decisive for their participation in everyday life. When all units of meaning had been identified, they were labelled and established as codes. After this, similarities between the codes were merged into categories, which came to represent clusters of meaning (41). In this first phase of the analysis, the authors found four categories that represented aspects of choice and control in semi-private spaces in the group homes. In the second phase of analysis, the authors incorporated the interview transcriptions. Practically, this meant that the authors read the transcriptions several times, and units of meaning in each interview were coded into the categories derived from the field notes. The transcriptions from resident and staff interviews were treated as two separate sets of data. The authors consciously determined if the coded meanings in the interview transcriptions represented a new category or could be clustered into existing ones. The coding process continued until all units of meaning related to the aim of study had been identified and categorised (50). However, no new categories were found relevant in this second phase of analysis. In order to reach trustworthiness and to increase its dependability, the coding of field notes and transcriptions into categories were discussed between the three authors until consensus was reached (41).

\section{Ethical considerations}


The study was approved by the Regional Research Ethics Board in Linköping (No. 2011/116-31) and the ethical guidelines from the Swedish Research Council (51) were followed. Consent was obtained from the residents, their guardians, staff and managers of the group homes according to the practice of obtaining informed consent. Written information given to residents with ID was adapted in accordance with their intellectual limitations (see for example 46-47). Oral informed consent from each informant was also obtained and recorded at the time of the interviews. To maintain confidentiality the names of the informants have been altered in the results section.

\section{Results}

We found four categories that can be understood as aspects of choice and control in the group homes' semi-private spaces in the everyday life of people ageing with ID. The first t category include space and objects as aspects of choice and control. The second include time and routines. The third category is focused on privacy in semi-private spaces, and the fourth and final category is focused on person-centred approaches.

The core of the group home - space and objects as aspects of choice and control

All semi-private spaces were located at and defined as the core of the group home. This is obvious since it is placed in the centre of the building, which made these spaces available and accessible for all residents. The location also meant that the residents continuously came and went between their own apartment and the common spaces. However, not all residents were able to take themselves to semi-private spaces on their own. Older residents with more comprehensive 
physical, cognitive or intellectual limitations, which made them unable to independently move in and out of their own apartment, spent more time in the semi-private space than the younger residents did. The older residents were also more staff-dependent when it came to entering and leaving the semi-private space, but also with regard to their physical placement in the room and their activity there.

The semi-private spaces, and not the residents' apartments, were defined and accepted by all as the central places for the social interaction and activities in the group home. However, those residents who were experiencing most age-related health changes, tended to spend a considerable time in their apartments. Both residents and staff discussed in the interviews that ageing and being old was related to physical, psychological and cognitive changes which negatively affected everyday participation in semi-private spaces. During the interviews with staff, however, the informants specifically mentioned the design of the semi-private spaces as barriers to participation. They described these spaces as narrow and with limited opportunities for activity, especially for older residents who, due to retirement, tend to spend more and more time in these spaces than they did earlier in life. They also mentioned that semi-private spaces were not decorated and furnished to facilitate the increased use of supportive technical devices such as wheelchairs and walkers. Thus, choice and control in the core of the group home were not only characterized by its location in the building, but also by its design and objects.

All semi-private spaces in this study were designed with the aim of creating a familiar environment. They included homelike and familiar objects that were significant for the activities expected to be performed in a home. These included art materials, DVDs, books and board games that notably were produced for young children. In the semi-private spaces there were also objects that residents needed in order to control and participate in different activities. Examples were 
equipment and technical aids, such as special chairs and adapted cutlery designed to compensate for residents physical limitations. However, the use of cognitive assistive devices, such as time aids or communication aids, was not observed in the semi-private spaces. In the interviews some staff mentioned that the lack of support was linked to ageing, and said that cognitive assistive devices were mainly prescribed to and used by younger people with ID.

Semi-private spaces also contained objects that could be regarded as institutional markers, and objects that residents could not control. Examples of such markers were objects used by staff in their work, such as staff timetables, binders for administration and lists of group home routines or medication taped to kitchen cupboards. Staff that sometimes wore nursing uniforms also contributed as institutional markers in the semi-private space.

The decoration and furnishing of the semi-private spaces were mainly controlled by staff. As a consequence, the staff also decided how the semi-private spaces should be used, e.g. which activities could be performed, and where these activities should take place. This also meant that there were particular activities that were frequently performed in semi-private spaces, which to some extent had their own predetermined micro spaces. The most frequent activities were related to cooking and dining, followed by watching television or movies. These activities meant that micro spaces, e.g. the TV -suite, the kitchen sink and the dining table, became frequent meeting points for residents and staff. Few other informal meeting points existed in the semi-private spaces.

Few negotiations were observed when it came to the use of the semi-private spaces. Activities were seldom discussed, either between members of staff or staff and residents, and few residents challenged the existence of these activities. However, on some occasions, negotiations regarding 
the use of spaces resulted in some residents who were able to move independently choosing to leave the semi-private space. This occurred, for example, when a resident did not like what was on the television, or what members of staff of other residents were talking about. Several residents also stated that it was important for them to be able to choose by themselves when to leave a semi-private space, as expressed by resident Lars, 71 years old:

It's important for me to decide when I can withdraw to my apartment and watch television at night.

However, there were also residents that revealed that they stayed in semi-private spacse despite disliking the manner of others' conversations, in order to please staff.

Mealtime and meantime - time and routines as aspects of choice and control

Scheduled meal and coffee times determined to a great extent when and how other activities were performed in the semi-private space and when it was socially accepted to enter and leave theses spaces. Preparing, cooking and having meals, and doing the dishes were observed and described as being central activities in semi-private spaces. Some residents were directly engaged in these activities, for example by choosing dishes for the menu, by peeling potatoes or setting the table. Others participated more passively by, for example, commenting on the menu or the smell of cooking. Food and meals were also frequent as subjects of conversation between the residents and staff. However, planning and preparing mealtimes were primarily controlled by group home routines and preferences of members of staff. The participation of residents in semi-private space activities was, however, almost solely described, by both staff and residents, as "helping staff'. This highlights that the semi-private spaces were seen primarily as an occupational arena 
controlled by the staff. This is shown in the following extract from a resident interview with Arne, 59 years old, and retired from work-related activities:

Arne: The staff ask me if I can peel the potatoes.

Interviewer: What do you do if you don't want to peel the potatoes?

A: I don't want to say that... No, I'm helpful, helping is good...

I: But why don't you say that you don't want to do it?

A: No... I'm not allowed to...

I: What do you think would happen if you say no?

A: Then the staff wouldn't like it... Who knows...?

The focus on mealtimes, including preparation and cooking, made the time between meals, a downtime to be filled until the next meal or coffee time. The open planning of semi-private spaces further strengthened the existence of this downtime since the sounds and smells of mealtime-related activities often filled the semi-private space as a whole. The most frequent downtime activity for the residents was watching television. In three of the group homes, the television was almost constantly on, from seven in the morning until nine or ten in the evening. In the fourth group home, a radio with a commercial channel playing seemed to fill the function of setting a kind of background atmosphere. These devices were usually controlled by members of staff, who appeared to pay little attention to what was on, and for whom.

Time and routines had a significant influence on residents' levels of choice and control. These levels seemed to be continuously changing; varying as the prerequisites for choice and control constantly changed in the semi-private space. This was observed, for example, when staff routinely prepared the weekly menu, or put on a DVD without asking for residents` preferences, 
or, as illustrated in the following field note, when staff habitually prepared breakfast in a way that was not preferred by all residents.

It is early morning in the group home's common kitchen. Sophie [staff] is preparing breakfast for the residents. She puts a large plate with cheese and cucumber sandwiches on the kitchen sink. As a routine these have been prepared a few hours ago by the night staff. Elsa, 70 years old [resident], enters the room... She takes one of the ready-made sandwiches from the plate. Instantly, she removes the cucumber and puts it in the trash can.

Extract from field note 4, November 2011

Elsa had her own way of controlling this situation, i.e. by throwing away the unwanted slice of cucumber. However, most residents ate their pre-made sandwiches without questioning.

In certain activities, residents' level of choice and control could change quickly. For example, when having breakfast, a resident could be asked by a member of staff to choose what to put on his morning bread at the same time as this same staff member poured orange juice into the resident's glass without asking if he wanted juice this morning or not.

Being private in semi-private spaces - privacy as an aspect of choice and control

Private matters were often handled in the semi-private space without the concerned resident's own choice and control. On those occasions the outcome was a consequence of decisions or actions controlled by group home staff or the routines. This was apparent when the semi-private space was used by staff to handle resident information of a private and sensitive nature. In the observations, this was exemplified by staff discussing a resident's private situation, such as personal care or a challenging behaviour, when sitting in the common kitchen dining area together with other residents. Another example was related to visits in the group home made by 
associated staff such as nurses or occupational therapists. In two observed cases this resulted in associated staff discussing a resident's private health matters when in the semi-private space, with others than the resident under discussion present. Several similar examples were observed in all four group homes. However, this was especially apparent in one of them. What distinguished this group home from the others was the absence of a separate space large enough for staff to have meetings in. In practice, this meant that all reports between staff were made sitting at a table in the common kitchen. This often resulted in residents being present when private matters of individuals were discussed. This group home even had a certain table in the semi-private space that was used for these reports, but this table was also used for doing all kinds of staff administration and also as the staff's own dining table. In one observed situation one of the residents came too close to this "staff table":

I am sitting at the "staff table" in the common kitchen writing field notes. Flora, 69 [resident] comes to talk with me. Anna [staff] enters the room. Anna tells Flora to go and sit on the sofa. - You know you must not stand here [by the "staff table"], she says to Flora. Flora leaves and sits down on the sofa [a few meters away]. Anna turns to me and explains that residents are not allowed to be near the "staff table", since it may contain documents about the residents, notes and talks that they [the residents] should not know about...

Extract from field note 19, December 2011

In this group home, the absence of appropriate spaces for administration and reporting had created a micro space within the semi-private space to which only group home staff could be admitted, a space threatening the privacy of the residents, a space beyond the residents`control. Traces of such micro spaces were also observed in the other group homes, although not described as such. 
To respect the person in the collective - person-centred approach as an aspect of choice and control

In order to support choice and control, the staff used what could be described as person-centred approaches. In practice, this could mean that a question, such as "what kind of fruit do you want?", needed to be asked in an individually adapted way in order to support the maximum level of choice and control for each of six residents. During the interviews, the staff stressed the importance of always asking for the residents preferences, in all kinds of activities, and evidence of such approaches was extensively found during observations. However, the use of personcentred strategies in semi-private spaces was complicated and not always possible. This was observed in all group homes and discussed by staff during the interviews. One example mentioned was that staff sometimes felt compelled to make decisions for the collective, or sometimes made decisions based on their own preferences. This kind of staff decision- making may at times interfere with residents' individual needs and wishes, as illustrated in this field note:

Five residents are having breakfast together at the common dining table. Two members of direct care staff, Mary and Helen, are also present. Paul, 77 [one of the residents] has finished his breakfast. He takes a snuff-box out of his pocket. -No snuff-box at the table, Mary says. Paul put away the snuff-box and asks if he is permitted to leave the table - No, say Mary and Helen at the same time. You must wait until everyone has finished. - But Christine [another resident] is ready, Paul says. -No, she is still eating, Helen says. You don't have an appointment, do you? - Yes I have, Paul says. Snuff time! - You should wait, Mary says.

Extract from field note 15, September 2011

In many situations similar to this one, group home routines, staff preferences or educative attitudes seemed to take precedence over residents' wishes and needs. This seemed to be disadvantageous, especially to older residents with more comprehensive physical, cognitive or intellectual limitations. A similar situation occurred in relation to the staffs' attitudes and knowledge about ageing in another group home. At the breakfast table, two members of staff 
discussed whether it was appropriate for the older residents to have apple juice for breakfast due to a general high risk of age-related diabetes. This discussion took place in front of residents and result was that suddenly none at the table were offered juice that morning. None of the residents took part in this discussion or reacted to its results.

Some staff also discussed whether the combination of age and lifelong disability inhibited choice and control. They said that it was harder to use person-centred approaches with older residents than with younger ones. They indicated that older residents had negative life course experiences related to their disability, which resulted in them having reduced interest or engagement in making their own decisions and speaking up for themselves, as well as reduced skills required for empowerment or self-advocacy.

On the basis of person-centred approaches, members of staff were important supporters of resident choice and control, but their actions (or non-actions) also constrained resident participation in the semi-private spaces. This was also discussed during the interviews, where the staff described themselves, in a reflective way, sometimes as improvers, and sometimes as inhibitors of the residents` choice and control.

In the interviews, the residents said that the staff made all the decisions in the group home. Several residents said that they often felt they needed the staff's permission to do things. However, this evidence of limited or low levels choice and control for several residents seemed to be associated with a feeling of safety and reliance. "When I want to make a change I just ask the staff", one resident said and meant this was a matter of confidence. Several residents stated that it was their own responsibility to make staff aware of changes that they wanted to implement 
in their everyday life, but their experience was that the staff were the ones who took the final decision.

\section{Discussion}

Our study shows that the level of choice and control is continuously influenced by the physical, social and cultural environment uniquely created in group homes. The study shows that choice and control are restricted by the interplay between this environment and age-related physical and psychological functional decrease. This is in line with Lawton's ecological model of ageing (5253), which is a well-used frame of reference for understanding how opportunities for participation are shaped by the interaction between a person, his or her capabilities and the surrounding environment. What our study adds is how ageing, as a multidimensional and interactive concept and phenomenon, shapes the outcome of choice and control in semi-private spaces.

Ageing is a lifelong process including physical, psychological and social dimensions (54-55). The social dimension of ageing includes for example attitudes and norms related to this concept, which affect an older person's opportunity for participation. Our study shows that resident choice and control can be restricted by staff attitudes and lack of knowledge about ageing and being old with ID. One example of this is the lack of cognitive assistive devices in semi-private spaces, and how the staff talked about its absence. It is well documented that the use of cognitive assistive devices, such as time aids or communication tools, among people with ID, can be decisive for their participation in everyday life (56-57), and also for people ageing with this disability (28-30, 58). Keeping older people with ID from getting access to cognitive assistive devices due to their 
chronological age could be an example of discriminative attitudes among the staff providing or giving access to these devices, often occupational therapists. Ageing understood as a multidimensional concept (54-55), including attitudes and norms related to ageing and being old, therefore needs to be integrated in occupational therapy theory and practice.

The ageing process is shaped by the individual's life course (59). Many older people with ID who live in group homes have been exposed to institutionalisation and stigmatization earlier in life (60). Such experiences are carried into old age, and can influence their ability and opportunities for participation throughout life to varying extents $(3,61)$. The development of contemporary Disability Policy (9) has changed living conditions and thereby also the conditions for choice and control in everyday life for these people. Nevertheless, their life course experiences of alienation, abuse, and staff control cannot be ignored. This study makes clear that choice and control in people ageing with ID could be restricted by these life course experiences. We therefore argue that discussions on occupational justice (36-37) for older people with ID need to be influenced by a life course perspective (see for example 54-55, 59). This study, and others $(22,38)$, could inform such a discussion. The life course perspective regards ageing as a dynamic process brought about by an interaction between individual, social and historical factors over time (59). Contemporary frameworks of occupational justice (37) explains how structural factors underlying occupation such as economy, policy, cultural values and support systems interact with contextual factors, such as individual, group, or community characteristics, and shape the outcomes of occupational justice or injustice. We argue that the life course perspective could be regarded as a continuous interface between structural and contextual factors related to occupational justice outcomes. The life course perspective could thereby strengthen the understanding of concepts 
related to occupational science, informing occupational therapy practice. However, these ideas need to be investigated and developed in further research.

This study found space and objects to be central to understanding levels of choice and control in semi-private spaces. Within occupational therapy, space and objects in the physical environment are regarded as important features for occupational participation (17). However, according to Cresswell (62), space connotes a realm without meaning. The findings in this study indicate however that space and objects in the group homes are more than environmental features. They shape the conditions for meaning and form the basis for everyday activities in the group home. This means that semi-private spaces need to be understood as places instead of spaces: they offer a way of seeing, knowing, understanding and giving meaning to the world (62). The idea of home has often been as a fundamental place that frames how people experience the world. However, in order for the semi-private place to become comparable with the idea of home, it needs to be a place with high levels of choice and control. However, this contrasts with the findings of this study.

It could be argued that an individual resident's choice and control, in one way or another, is restricted in semi-private spaces. Such a restriction is an inevitable consequence of collective living. The fact that several individuals share the same spaces on an everyday basis in itself entails accommodation and negotiation. The levels of choice and control in this study seem to be constantly shaped by the physical environment, e.g. spaces and objects in semi-private spaces, and by the organisational culture of the group home, such as routines and working methods. This is in accordance with earlier studies on participation among people ageing with ID, and confirms that participation is a multidimensional concept (14-17). However, what is significant in the present study is the dominant role of group home staff in setting the conditions for residents' 
choice and control. This was found in all result categories in this study. Previous research has discussed how semi-private spaces can be used to exercise staff power $(6,8)$. The group home is both a working place for staff and a community-based institutional living that is collective in nature. Still, this living facility should be regarded as a home-like place (62) without giving the impression of being an institution (5). The risks and effects of institutionalisation on a person's opportunities for participation in everyday life should therefore always be respected. We thereby argue that it is important that staff become aware of, and actively try to balance their powerful position in semi-private spaces. Staff use what could be called person-centred approaches in an attempt to do this. However, we have also shown that such an approach is not always adopted or possible. Person-centredness seems to be hindered by group home routines as well as staff preferences. Nevertheless, the person-centred approach is advocated in the Swedish Disability Act (5). The individual's perspective, needs, and desires should thus be the driving force of support and service. This is also in line with the concept of occupational justice (37) and the person-centred approach within occupational therapy, which recognize an individual's knowledge, strengths, capacity for choice, and overall predisposition toward empowerment (6364). Based on this, occupational therapy interventions can and should support choice and control in people ageing with ID. Since older people tend to spend increasingly more time in semiprivate spaces, it is important that occupational therapists integrate this occupational arena in their evaluations and interventions. This could for example be done by person-centred occupational therapy evaluations and interventions such as rearranging and adapting the physical environment or introducing the use of cognitive assistive devices. However, direct or indirect supervision of staff in person-centred approaches and how to increase resident empowerment in semi-private spaces are other issues for occupational therapists to consider in practice. 
This study has contributed to the understanding of how and when choice and control in semiprivate spaces can be exercised by people ageing with ID, and how choice and control could be limited by staff or the social or physical environment. The study is one of the first in Sweden when it comes to participation in people ageing with ID. However, further research is needed on other aspects of resident participation, and of participation in society in general in regard to the growing group of people ageing with ID.

\section{Methodological considerations}

This qualitative study involved a small number of study settings and informants, which must be taken into consideration when discussing and implementing its findings. However, the four different group homes were rather similar and the conditions of the study settings could be transferable to other group home settings for people with ID in the Scandinavian countries and probably also in a wider international context. This study included the subjective experiences of people with ID. This perspective has been regarded as difficult to investigate $(12,47-49,65)$. However, doing so, and developing suitable study designs is important for improving the wellbeing of this group. In order to overcome the methodological difficulties involved in interviewing people with ID the authors used several strategies, such as asking the questions in a concrete way, and using pictures as a complement to written and/or oral questions $(12,46-47)$. The use of these strategies strengthens the trustworthiness of the results. The perspectives of group home staff included in this study are, however, also important when exploring participation in this group. In an earlier study, group home residents ageing with ID accredited staff with increased importance as they and other residents became older (38). Additionally, staff 
perspectives, such as working methods, ambitions and values, have been shown to be important for what staff actually do (66) and thus for residents' wellbeing (13). By combining participant observations with qualitative interviews we were able to delve deeper into the understanding of the phenomenon being studied (41-42). We therefore argue that the design of this study strengthens the trustworthiness of its results.

Acknowledgement The authors would like to express their gratitude to Professor Joy Hammel, Department of Occupational Therapy, University of Illinois at Chicago, USA, for her constructive and supportive comments during the writing of this article.

Declaration of interest The authors report no conflicts of interest. The authors alone are responsible for the content and writing of the paper.

\section{References}

1. Socialstyrelsen. Official statistics of Sweden. Statistics - Social welfare. Persons with certain functional impairments measures specified by LSS 2013. Stockholm: Socialstyrelsen, 2014 [In Swedish with a summary in English].

2. Bigby C, Haveman M. Aging... A continuing challenge. J Policy Pract Intellect Disabil 2010; 7:1-2.

3. Bigby C. Ageing with a lifelong disability. A guide to practice, program and policy issues for human services professionals. London: Jessica Kingsley Publisher, 2004.

4. World Health Organization. Healthy ageing - Adults with intellectual disabilities: summative report. J Appli Res Intellect Disabil 2001; 14: 256-75.

5. SFS. Svensk författningssamling [Swedish Code of Statues]. Lagen om stöd och service till vissa funktionshindrade [The act concerning support and service for persons with certain functional impairments], 1993:387 [In Swedish].

6. Olin E, Ringsby Jansson B. Common areas in group homes: arenas for different interests? European Journal of Social Work 2008; 11: 251-65.

7. Nord C. Architectural space as a moulding factor of care practices and resident privacy in assisted living. Ageing Soc 2011; 31: 934-952.

8. Clement T, Bigby C. Group homes for people with intellectual disabilities. Encouraging inclusion and participation. London: Jessica Kingsley Publishers, 2010.

9. Government Office of Sweden. Objectives and priorities for the disability area. [cited 2013 Nov 1]. Available from: URL: http://www.government.se/sb/d/15472/a/184236

10. Nirje B. The normalization principle and its human management implications. In Kuge R, Wolfensberger, W. eds. Changing patterns in residential service for the mentally retarded. Washington D.C.: President's committee on mental retardation, 1969.

11. Ericsson K. From institutional life to community participation. Ideas and realities concerning support to persons with intellectual disability. PhD diss. Uppsala University, 2002.

12. Kjellberg A. Participation - Ideology and everyday life. How to understand the experiences of persons with learning disabilities. PhD diss. Linköping University, 2002. 
13. Kozma A, Mansell J, Beadle-Brown J. Outcomes in different residential settings for people with intellectual disability: A systematic review. Am J Intellect Dev Disabil 2009; 114: 193-222.

14. Hammel J, Magasi S, Heinemann A, Whiteneck G, Bogner J, Rodrigeuz E. What does participation mean? An insider perspective from people with disabilities. Disabil Rehabil 2008; 30: 1445-60.

15. Hemmingsson H, Jonsson $\mathrm{H}$. The issue is - an occupational perspective on the concept of participation in the international classification of functioning, disability and health - some critical remarks. Am J Occup Ther 2005; 59: 569-76.

16. Nordenfelt L. Action theory, disability and ICF. Disabil Rehabil 2003; 25:1075-9.

17. Kielhofner, G. A Model of Human Occupation. Theory and application. $4^{\text {th }}$ ed. Philadelphia: Lippincott Williams \& Wilkins, 2008.

18. World Health Organization. International Classification of Functioning, Disability and Health (ICF). Geneva: World Health Organization, 2001.

19. Kramer J, Bowyer P, Kielhofner G. The model of human occupation, the ICF, and the occupational therapy practice framework: Connections to support best practice around the world. In Kielhofner G, ed. Model of Human Occupation. Theory and application, $4^{\text {th }}$ ed. Philadelphia: Lippincott Williams \& Wilkins, 2008: 519-531.

20. Wessby K, Kjellberg A. Participation in occupational therapy research: a literature review. Br J Occup Ther 2010; 73: 319-26.

21. Dusseljee J C E, Rijken P M, Curfs L M G, Groenewegen P P. Participation in daytime activities among people with mild or moderate intellectual disability. J Intellect Disabil Res 2011; 55: 4-18.

22. Kåhlin I, Kjellberg A, Hagberg J E. Staff Experiences of Participation in Everyday Life of older People with Intellectual Disability who live in Group Homes. Scand J Disabil Res 2014. Available on http://dx.doi.org/10.1080/15017419.941923

23. Ellison C, White A, Chapman L. Avoiding institutional outcomes for older adults living with disability: The use of community-based aged care support. J Intellect Dev Disabil 2011; 36: 175-83.

24. Judge J, Walley R, Anderson B, Young R. Activity, aging, and retirement: The views of a group of Scottish people with intellectual disabilities. J Policy Pract Intellect Disabil 2010; 7: 295-301.

25. Bigby C, Webber R, Bowers B, McKenzie-Green B. A survey of people with intellectual disabilities living in residential aged care facilities in Victoria. J Intellect Disabil Res 2008; 52: 404-14.

26. Bigby C. Comparative program options for aging people with intellectual disabilities. J Policy Pract Intellect Disabil 2005; $2: 75-85$.

27. Webber R, Bowers B, McKenzie-Green B. 2010. Staff responses to age-related health changes in people with an intellectual disability in group homes. Disabil Soc 2010; 25: 657-71.

28. Mizra M, Hammel J. Consumer-directed goal planning in the delivery of assistive technology services for people who are ageing with intellectual disabilities. J Appli Res Intellect Disabil 2009; 22: 445-57.

29. Hutchings B L, Olsen R V, Moulton H J. Environmental evaluations and modifications to support aging at home with a developmental disability. J Hous Elderly 2008; 22: 286-310.

30. Hammel J, Lai J-S, Heller T. The impact of assistive technology and environmental interventions on function and living situation status with people who are ageing with developmental disabilities. Disabil Rehabil 2002; 24:93-105.

31. Ingvaldsen A K., Balandin S. "If we are going to include them we have to do it before we die": Norwegian seniors' views of including seniors with intellectual disability in senior centers. J Appli Res Intellect Disabil 2011; 24: 583-93.

32. Bigby C, Wilson N J, Balandin S, and Stancliffe R J. Disconnected expectations: Staff, family, and supported employee perspective about retirement. J Intellect Dev Disabil 2011; 36: 167-74.

33. Webber R, Bowers B, Bigby C. Hospital experiences of older people with intellectual disability: Responses of group home staff and family members. J Intellect Dev Disabil 2010; 35: 155-64.

34. Lifshitz, H. Later life planning training program: A pre-test assessment in Israel. J Gerontol Soc Work 2002; 37: 87103.

35. Molin M. Att vara i särklass - Om delaktighet och utanförskap i gymnasiesärskolan [To be special in class - on participation and alienation in upper secondary school for pupils with intellectual disabilities]. PhD diss. Linköping University, 2004a [In Swedish with a summary in English].

36. Nilsson I, Townsend E. Occupational Justice - Bridging theory and practice. Scand J Occup Ther 2010; 17: 57-63.

37. Stadnyk R, Townsend E, Wilcock A. Occupational Justice. In Cristiansen C, Townsend E, eds. Introduction to Occupation. New Jersey: Pearson, 2011: 329-358.

38. Kåhlin I, Kjellberg A, Nord C, Hagberg J-E. Lived experiences of ageing and later life in older people with intellectual disabilities. Ageing Soc. Available on CJO 2013 doi: 10.1017/S0144686X13000949.

39. Hammersley M, Atkinson P. Ethnography, Principles in practice. $3^{\text {rd }}$ ed. London: Routledge, 2007.

40. Taylor S J, Bogdan S. Introduction to Qualitative research methods. A guidebook and resource. $3^{\text {rd }}$ ed. New York: John Wiley and sons, Inc., 1998.

41. Patton M Q. Qualitative Research \& Evaluation Methods. London: SAGE Publications Inc., 2002. 
42. Borell L, Nygård L, Asaba E, Gustavsson A, Hemmingsson H. Qualitative approaches in occupational therapy research. Scand J Occup Ther 2012; 19:521-9.

43. Schalock R L, Borthwick-Duffy S A, Bradley V J, Buntinx W H E, Coulter D L, Craig E M, Gomez S C, Lachapelle Y, Luckasson R, Reeve A, Shogren K A, Snell M E, Spreat S, Tassé M J, Thompson J R, Verdugo-Alonso M A, Wehmeyer M L,Yeager M H. Intellectual Disability: Definition, Classification, and Systems of Supports (Eleventh edition). Washington: American Association of Intellectual and Developmental Disabilities, AAIDD, 2010.

44. Kvale S. Interviews. An introduction to qualitative research interviewing. London: SAGE Publications Inc., 1996.

45. Giorgi A. The descriptive phenomenological methods in psychology. A modified Husserlian approach. Pittsburgh, Pennsylvania: Duquense University Press, 2009.

46. Folkestad H. Getting the picture: Photo-assisted conversation as interviews. Scand J Disabil Res 2000; 2: 3-21.

47. Nind M. Conducting qualitative research with people with learning, communication and other disabilities: Methodological challenges. ESRC National Centre for Research methods review paper, University of Southampton, 2008.

48. Brewster S J. Putting words into their mouths? Interviewing people with learning disabilities and little/no speech. British Journal of Learning Disabilities 2004; 32: 166-9.

49. McVilly K R. Interviewing people with learning disabilities about their residential service. British Journal of Learning Disabilities 1995; 23: 138-42.

50. Hsieh H, Shannon S E. Three approaches to qualitative content analysis. Qual Health Res 2005; 15: 1277-88.

51. Swedish Research Council. Good research practice. Stockholm: Swedish Research Council, Stockholm, 2011.

52. Lawton M. P. Environment and aging: Theory revisited. In Scheidt R, Windley P. eds. Environment and aging theory: A focus on housing. Westport, CT: Greenwood Press, 1998: 1-32.

53. Lawton M. P, Nahemow L. 1973. Ecology and the aging process. In Eidsdorfer C, Lawton M. eds. Psychology of adult development and aging. Washington: American Psychological Association, 1973: 619-674.

54. Dannefer D, Phillipson C. eds. The SAGE Handbook of Social Gerontology. London: SAGE Publications Ltd, 2010.

55. Johnson M. L. ed. The Cambridge Handbook of Age and Ageing. Cambridge: Cambridge University Press, 2005.

56. Wennberg B, Kjellberg A. Participation when using cognitive assistive devices - from the perspective of people with intellectual disabilities. Occup Ther Int 2010; 17: 159-207.

57. Arvidsson G, Jonsson $\mathrm{H}$. The impact of time aids on independence and autonomy in adults with developmental disabilities. Occup Ther Int 2006; 13: 160-75.

58. Hammel J. Assistive technology and environmental intervention (AT-EI) impact on the activity and life roles of aging adults with developmental disabilities: findings and applications for practice. Phys Occup Ther Geriatr 2000; 18: 37-58.

59. Holstein J. A, Gubrium J. F. Constructing the Life Course. New York: General Hall, 2000.

60. Goffman E. Asylums. Essays on the social situation of mental patients and other inmates. New York: Anchor Books, 1961.

61. Thorsen K. Mennesker med utviklingshemning og livsberetninger om livslop og aldring [People with intellectual disability and life stories on life course and ageing] In Thorsen K, Jeppsson Grassman E. eds. Livsløp med funksjonshemming [Life course with disability]. Oslo: Cappelen Damm Akademisk, 2012: 150-88 [In Norwegian].

62. Cresswell, T. Place - a short introduction. Oxford: Blackwell Publishing, 2004

63. Kjellberg A, Kåhlin I, Haglund L, Taylor R. The myth of participation in occupational therapy: reconceptualizing a client centered approach. Scand J Occup Ther, 2012; 19: 421-427.

64. Townsend E. Enabling occupation: An occupational therapy perspective. Ottawa: Canadian Association of Occupational Therapists; 2002.

65. Booth T, Booth W. Sounds of silence: Narrative research with inarticulate subjects. Disabil Soc1996; 11: 55-69.

66. Bigby C, Knox M, Beadle-Brown J, Clement T, Mansell J. Uncovering dimensions of culture in underperforming group homes for people with severe intellectual disability. Intellect Dev Disabil 2012; 50: 452-67. 